\title{
How can we prevent staff-to-staff transmission of coronavirus?
}

\author{
Andrew Moscrop general practitioner \\ Luther Street Medical Centre, Oxford OX1 1UL, UK
}

In the absence of clear guidance, primary care teams have formulated their own methods to prevent staff-to-staff transmission of coronavirus. ${ }^{1}$ I talked with staff at four health centres in Oxford, who said the following measures were being used:

Minimise staff in the workplace. Home working for administrative and clinical staff becomes increasingly feasible as patient footfall reduces, remote consultations increase, and technological challenges are overcome

Replace face-to-face with online team meetings. Software is free and hardware is cheap

Ensure everyone washes their hands on entering and departing the building. Patient facing staff should change clothes at the beginning and end of the day, ideally wearing scrubs in between

Minimise sharing of workspaces and equipment

Establish daily disinfectant wiping of communal surfaces, door handles, light switches, chairs, keyboards, and telephones

Don't make cups of tea for your colleagues. Or bring in cakes. Sorry

Encourage staff to self-monitor and report any potential covid symptoms

Manage face-to-face encounters with staff just as with patients: maintain distance, minimise duration, and wear face masks if appropriate and supplies permit
Ensure that changes to practice are communicated clearly to all staff, reviewed or audited, and results shared with staff Support other team members. Clinical staff face new and challenging clinical and ethical decisions, which might be supported by working with a "buddy." Some staff will have vulnerable or unwell family or friends and might require additional emotional support. Changes to job roles and working practices will be unsettling for some staff members, and some changes might have to be compromised for the sake of cohesion

Finally, not infection control, but related to staff health-NHS staff now have free access to a range of wellbeing apps when using an NHS email address to register.

Many thanks to John Frank at the Observatory Medical Practice in Oxford, Sharon Dixon and Alan Mordue at the Donnington Health Centre, Margaret Reeves at the Cowley Road Medical Practice, and Stephen Moore at the Luther Street Medical Centre for sharing their experiences and working practices.

Competing interests: None declared.

Full response at: https://www.bmj.com/content/368/bmj.m1182/rr-11

Greenhalgh T, Koh GCH, Car J. Covid-19: a remote assessment in primary care. BM 2020;368:m1182. 10.1136/bmj.m1182 32213507

Published by the BMJ Publishing Group Limited. For permission to use (where not already granted under a licence) please go to http://group.bmj.com/group/rights-licensing/ permissions 